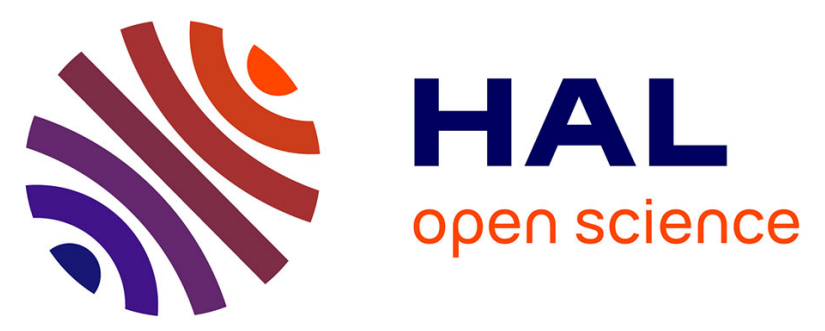

\title{
New polymer electrolyte membrane for medium-temperature fuel cell applications based on cross-linked polyimide Matrimid and hydrophobic protic ionic liquid
}

S. Rogalsky, Jean-François Bardeau, S. Makhno, O. Tarasyuk, N. Babkina, T. Cherniavska, M. Filonenko, K. Fatyeyeva

\section{To cite this version:}

S. Rogalsky, Jean-François Bardeau, S. Makhno, O. Tarasyuk, N. Babkina, et al.. New polymer electrolyte membrane for medium-temperature fuel cell applications based on cross-linked polyimide Matrimid and hydrophobic protic ionic liquid. Materials Today Chemistry, 2021, 20, pp.100453. 10.1016/j.mtchem.2021.100453 . hal-03326567

\section{HAL Id: hal-03326567 https://hal.science/hal-03326567}

Submitted on 3 Nov 2021

HAL is a multi-disciplinary open access archive for the deposit and dissemination of scientific research documents, whether they are published or not. The documents may come from teaching and research institutions in France or abroad, or from public or private research centers.
L'archive ouverte pluridisciplinaire HAL, est destinée au dépôt et à la diffusion de documents scientifiques de niveau recherche, publiés ou non, émanant des établissements d'enseignement et de recherche français ou étrangers, des laboratoires publics ou privés. 


\title{
New polymer electrolyte membrane for medium-temperature fuel cell applications based on cross-linked polyimide Matrimid and hydrophobic protic ionic liquid
}

\author{
S. Rogalsky ${ }^{\text {a, * }}$, J.-F. Bardeau ${ }^{\text {b }}$, S. Makhno ${ }^{c}$, O. Tarasyuk ${ }^{\text {a }}$, N. Babkina ${ }^{\text {d }}$, T. Cherniavska ${ }^{\text {, }}$, \\ M. Filonenko ${ }^{\mathrm{e}}$, K. Fatyeyeva ${ }^{\mathrm{f}}$ \\ ${ }^{a}$ V. P. Kukhar Institute of Bioorganic Chemistry and Petrochemistry of National Academy of Sciences of Ukraine, Laboratory of Modification of Polymers, 50 \\ Kharkivske Schose, 02160, Kyiv, Ukraine \\ b Institut des Molécules et Matériaux Du Mans, UMR CNRS 6283, Université Du Maine, Université Bretagne - Loire, Avenue Olivier Messiaen, 72085 \\ Le Mans Cedex 9, France \\ c Chuiko Institute of Surface Chemistry of National Academy of Sciences of Ukraine, Laboratory of Electrophysics of Nanomaterials, 17, General Naumov Str., \\ 03680, Kyiv, Ukraine \\ ${ }^{\mathrm{d}}$ Institute of Macromolecular Chemistry of National Academy of Sciences of Ukraine, Department of Physics and Chemistry of Polymers, 48, Kharkivske \\ Schose, 02160, Kyiv, Ukraine \\ e National Pedagogical Dragomanov University, Faculty of Physics and Mathematics, 9, Pyrogova St., 01601, Kyiv, Ukraine \\ ${ }^{\mathrm{f}}$ Normandie Univ, UNIROUEN, INSA Rouen, CNRS, Polymerès Biopolymères Surfaces (PBS), 76000, Rouen, France
}

\begin{abstract}
A B S T R A C T
New hydrophobic protic ionic liquid, 2-butylaminoimidazolinium bis(trifluoromethylsulfonyl)imide (BAIM-TFSI), has been synthesized. The ionic liquid showed good thermal stability to at least $350{ }^{\circ} \mathrm{C}$. The conductivity of BAIM-TFSI determined by electrochemical impedance method was found to be $5.6 \times 10^{-2} \mathrm{~S} / \mathrm{cm}$ at $140{ }^{\circ} \mathrm{C}$. Homogeneous composite films based on commercial polyimide (PI) Matrimid and BAIM-TFSI containing 30-60 wt\% of ionic liquid were prepared by casting from methylene chloride solutions. Thermogravimetric analysis data indicated an excellent thermal stability of PI/BAIMTFSI composites and thermal degradation points in the temperature range $377^{\circ} \mathrm{C}-397^{\circ} \mathrm{C}$. The addition of ionic liquid up to $50 \mathrm{wt} \%$ in PI films does not lead to any significant deterioration of the tensile strength of the polymer. The dynamic mechanical analysis results indicated both an increase of storage modulus $E^{\prime}$ of PI/BAIM-TFSI composites at room temperature and a significant $E^{\prime}$ decrease with temperature compared with the neat polymer. The cross-linking of the PI with polyetheramine Jeffamine D- 400 allowed to prepare PI/Jeffamine/BAIM-TFSI (50\%) membrane with $E^{\prime}$ value of $300 \mathrm{MPa}$ at $130{ }^{\circ} \mathrm{C}$. The ionic conductivity of this cross-linked composite membrane reached the level of $10^{-2} \mathrm{~S} / \mathrm{cm}$ at $130{ }^{\circ} \mathrm{C}$, suggesting, therefore, its potential use in medium-temperature fuel cells operating in water-free conditions.
\end{abstract}

\section{Introduction}

Polymer electrolyte membrane fuel cells are considered as promising alternative energy sources for stationary, automotive, and portable applications because of their high efficiency in converting chemical energy stored in hydrogen fuel directly into electrical energy, with water being the only by-product. The main functions of polymer electrolyte membrane or proton exchange

\footnotetext{
* Corresponding author.

E-mail address: sergey.rogalsky@gmail.com (S. Rogalsky).
}

membrane (PEM) are to avoid direct contact between fuel and air as well as to ensure efficient proton transfer from the anode to cathode side [1]. Low-temperature PEM fuel cells working at about $80{ }^{\circ} \mathrm{C}$ with perfluorosulfonic acid ionomers (e.g., Nafion) as electrolyte have been widely used for a long time. In the hydrated state, Nafion membranes have excellent proton conductivity because of the formation of continuous ion-conducting clusters by both sulfonic groups and water molecules [2]. However, the high-temperature PEM fuel cells operating in the temperature range of $120{ }^{\circ} \mathrm{C}-200{ }^{\circ} \mathrm{C}$ are more promising because of their significant advantages, such as increased tolerance to catalyst poisoning by carbon dioxide, enhanced electrode kinetics, easier heat 
dissipation, and water management $[3,4]$. Under such conditions, Nafion membranes lose their conductivity because of water evaporation [4].

Polybenzimidazole (PBI) impregnated with phosphoric acid is commercially available proton-conducting system, which provides good level of proton conductivity above $100{ }^{\circ} \mathrm{C}$ without external humidification $[3,5,6]$. In PBI matrix, $\mathrm{H}^{+}$ions can migrate through the polymer backbone by means of hydrogen bonds, assisted by phosphate anions [3,5]. However, $\mathrm{PBI} / \mathrm{H}_{3} \mathrm{PO}_{4}$ membranes have such drawbacks as partial loss of phosphoric acid (that leads to reduced proton conductivity) when the operating temperature of the fuel cells is below $100{ }^{\circ} \mathrm{C}[5,6]$. It should also be noted that the cost of both Nafion and PBI-based PEMs remains still high.

During the last decades, various approaches have been proposed to develop alternative PEM for high-temperature fuel cell applications at reasonable cost. Thus, sulfonated poly(ether ether ketone) (SPEEK) as well as other sulfonated rigid aromatic polymers, such as polyphenylsulfone, polyethersulfone, and polyimides (PIs), were studied as possible alternative ionomers [3,6-11]. Both organic and inorganic solid proton-conducting electrolytes have also been developed for water replacement in PEM, such as imidazole derivatives [8], heteropolyacids [9], zirconium phosphate [10], and polyaniline [11-13]. Composite membranes, based on zirconium phosphate or calcium phosphate and imidazolium-based aprotic ionic liquids, supported on polytetrafluoroethylene, were found to have excellent anhydrous proton conductivity at high temperature of $200{ }^{\circ} \mathrm{C}[14,15]$. The ionic liquid component was supposed to act as a proton bridge [14].

Recently, the protic ionic liquids (PILs), which are low-temperature molten salts of Brønsted acids and Brønsted bases, have proved to be extremely promising proton-conducting electrolytes for fuel cells applications [16-20]. In contrast to aprotic ionic liquids, PILs have a mobile proton located on the cation, which can be transferred from the acid to the base, which offers intrinsic proton conductivity. The presence of proton donor and proton acceptor sites can thus be used to build a hydrogen-bonded network [16,21]. The proton conduction in PILs was found to proceed by two parallel mechanisms: diffusion and hopping (Grotthuss mechanism) $[16,17]$. The most studied PILs contain imidazolium, triethylammonium, diethylmethylammonium cations, and fluorocontaining anions, such as trifluoromethanesulfonate and bis(trifluoromethylsulfonyl)imide [16-19]. The ionic conductivity of PILs is commonly in a range from $10^{-3}$ to $10^{-1} \mathrm{~S} / \mathrm{cm}$ both at room temperature and above $100{ }^{\circ} \mathrm{C}$ [16-18]. Moreover, these compounds possess negligible vapor pressure, high thermal stability, and nonflammability, as well as wide electrochemical window [19-21].

Composite films based on sulfonated aromatic polymers and PILs were found to be prospective alternative PEMs for high-temperature fuel cell applications. Thus, new composite membrane has been developed on the base of SPEEK and ionic liquid trifluoroacetic propylamine (TFAPA). Conductivity of $0.019 \mathrm{~S} / \mathrm{cm}$ was achieved for SPEEK/TFAPA membranes containing $70 \mathrm{wt} \%$ of ionic liquid at $160{ }^{\circ} \mathrm{C}$ [22]. Unfortunately, these composites showed poor mechanical strength, especially at elevated temperatures. Inorganic-organic composite membranes have also been developed based on SPEEK, silica, and PIL diethylmethylammonium trifluoromethanesulfonate [dema][TfO] [23]. A proton conductivity of $0.02 \mathrm{~S} / \mathrm{cm}$ was obtained for composites containing $50 \mathrm{wt} \%$ of ionic liquid at $220^{\circ} \mathrm{C}$. However, dynamic mechanical analysis (DMA) data indicated significant drop of storage modulus for both SPEEK/SiOx and SPEEK/SiOx/[dema][TfO] membranes above $80^{\circ} \mathrm{C}$ [23].

Among many advanced polymer matrices, sulfonated aromatic PIs (SPIs) are probably one of the most promising PEMs for use in fuel cells because they combine both good film-forming properties, excellent mechanical strength and thermal stability. Elaboration of composite membranes based on SPIs and PILs has recently been reported [24-26]. It is worth noting that the presence of sulfonic groups in PI macromolecules results in solubility in polar solvents, as well as significantly improved compatibility between polymer matrix and PIL [24,26]. Thus, SPI membranes with the ion exchange capacity of $2.27 \mathrm{mEq} / \mathrm{g}$ were found to retain four times its own weight of [dema][TfO] ionic liquid, and uniform, tough, and transparent films were obtained by solvent casting [24]. The composite membranes have good thermal stability $\left(>300^{\circ} \mathrm{C}\right)$ and ionic conductivity above $10^{-2} \mathrm{~S} / \mathrm{cm}$ at $120^{\circ} \mathrm{C}$ under anhydrous conditions when the [dema][TfO] content is higher than $67 \mathrm{wt} \%$. Deligöz and Yilmazoğlu [25] reported the development of complex membranes based on SPI comprising 1-methylimidazolium cations. Although the membranes doped with sulfuric acid revealed the ionic conductivity of $5.6 \times 10^{-2} \mathrm{~S} / \mathrm{cm}$ at $180^{\circ} \mathrm{C}$, they were characterized by a high hydrophilicity and poor thermal stability of conductivity because of the evaporation of adsorbed dopant. In the case of PEM based on SPI and PILs comprising TfO anion and 1methylimidazolim or 1-vinylimidazolium cations [26], they were found to be flexible and transparent, with a good thermal stability $\left(>350^{\circ} \mathrm{C}\right.$ ) and high ionic conductivity $\left(3-6 \mathrm{mS} / \mathrm{cm}\right.$ ) at $120^{\circ} \mathrm{C}$ (at the ionic liquid content of $40-50 \mathrm{wt} \%$ ). However, tensile strength values of SPI/PIL composites were found to be almost one order lower compared with neat SPI [26]. Successful approach has finally been reported by Pua et al. [8] when hydrophobic heterocyclic amine 2-undecylimidazole was used as an efficient proton-conducting additive. The proton conductivity of such composite reached $10^{-3} \mathrm{~S} / \mathrm{cm}$ at $180{ }^{\circ} \mathrm{C}$.

Overall, the disadvantage of SPI is the use of toxic high boiling point solvents such as $m$-cresol or $N$-methyl-2-pyrrolidone/ dimethyl sulfoxide for both polymer synthesis and film casting [24-26]. Such solvents are rather difficult to remove entirely from composite membranes and cause deterioration of composite thermomechanical properties. Moreover, the sulfonation of aromatic PI always leads to significant increase in their cost, as well as high hydrophilicity of membranes.

Accordingly, the use of nonsulfonated rigid chain polymers as a matrix for composite PEM seems very attractive from a practical point of view. However, aromatic PIs are poorly compatible with hydrophilic PILs such as [dema][TfO] [24]. To avoid this problem, the microporous support based on commercial PI Matrimid was impregnated with hydrophilic PIL, triethylammonium trifluoromethanesulfonate (TEA-TF), to obtain composite PEM with ionic liquid content up to $76 \mathrm{wt} \%$ [27]. At $130{ }^{\circ} \mathrm{C}$, the membrane exhibits proton conductivity of $20 \mathrm{mS} / \mathrm{cm}$ that is very close to that of the pure PIL. In other study, Matrimid membrane with spongy, interconnected, and symmetrical porous structure was impregnated with hydrophilic PIL, 1-butylimidazolium dibutyl phosphate, by direct immersion method [28]. The composite PEM containing at least $50 \% \mathrm{v} / \mathrm{v}$ of ionic liquid phase showed good retention in the polymer matrix. The ionic conductivity reached the value of $2 \times 10^{-2} \mathrm{~S} / \mathrm{cm}$ at $115{ }^{\circ} \mathrm{C}[28]$. However, it should be noted that the porous polymer support, as well as its composite with PIL, had significantly reduced mechanical properties compared with dense PI films [27].

The hydrophobic PIL, 1-butylimidazolium bis(trifluoromethylsulfonyl)imide (BIM-TFSI), was found to have good compatibility with PI Matrimid [29]. Thus, due to the good solubility of Matrimid in common organic solvents, dense composite films containing up to $70 \mathrm{wt} \%$ of BIM-TFSI were prepared by casting from methylene chloride solution. Polyetheramine Jeffamine D2000 was used as a cross-linking agent for PI to obtain composite membranes with satisfactory tensile strength of $18 \mathrm{MPa}$. The ionic conductivity reached $1.5 \times 10^{-3} \mathrm{~S} / \mathrm{cm}$ at $180^{\circ} \mathrm{C}$ that was close to the 
conductivity of pure PIL [29]. Thus, the results of previous studies indicated the possibility of obtaining PEMs based on dense Matrimid PI films and PILs. The main difficulty is to choose an appropriate hydrophobic PIL, which combines high proton conductivity, thermal stability, and good compatibility with PI matrix. From this point of view, the high content of exchangeable protons in the ionic liquid structure seems to be especially important because in such a case, we can expect both high conductivity and strong physicochemical interactions with polar carbonyl groups of PI.

Guanidinium-based ionic liquids are known to be very promising proton conductors due to the presence of six dissociable protons in guanidinium cation [30,31]. On the other hand, the high melting point of most guanidinium salts is a serious drawback for their application as proton-conducting electrolyte. Reducing symmetry of cations can reduce the melting points, and a series of room temperature PILs comprising both common and cyclic guanidinium cations and TFSI anion have been synthesized [32-34]. However, the substitution of hydrogen atoms on alkyl radicals in the guanidinium cation led to decreased proton conductivity [32,33]. New PIL based on monosubstituted guanidinium cation, N-butylguanidinium tetrafluoroborate, has been synthesized by single-step method. The ionic liquid is thermally stable to at least $300{ }^{\circ} \mathrm{C}$ and has ionic conductivity value of $0.18 \mathrm{~S} / \mathrm{cm}$ at $180^{\circ} \mathrm{C}$ [35]. However, Nbutylguanidinium salts were found to be insoluble in low-boiling solvents like methylene chloride or tetrahydrofuran and, therefore, seem to be less attractive for the elaboration of composite membranes based on Matrimid.

In the present study, new room temperature PIL comprising cyclic guanidinium cation, 2-butylaminoimidazolinium bis(trifluoromethylsulfonyl)imide (BAIM-TFSI) has been synthesized. This ionic liquid is soluble in methylene chloride, and the composite films PI/BAIM-TFSI were easily prepared by solvent casting. Moreover, because of its hydrophobic nature, BAIM-TFSI has significant advantages over common hydrophilic PILs, such as excellent compatibility with PI, as well as potential leaching resistance from PEMs during fuel cell operation. The obtained membranes were then characterized in terms of mechanical properties, thermal stability, and proton conductivity in a wide range of temperature.

\section{Materials and methods}

\subsection{Materials}

Following chemicals were used for the synthesis of ionic liquid and for the elaboration of PI-based composites: 2imidazolidinethione, 98\% (Fluka), n-butylamine, 99\% (Merck), polyetheramine Jeffamine D-400 (Huntsman), lithium bis(trifluoromethylsulfonyl)imide, 99\% (Acros), methanol, 98\% (SigmaAldrich), hydrochloric acid, 37\% (Sigma-Aldrich), isopropanol, 98\% (Sigma-Aldrich), and methylene chloride, 99\% (Sigma-Aldrich).

PI Matrimid 5218 powder was kindly supplied by Huntsman (Switzerland).

\subsection{Synthesis of PIL BAIM-TFSI}

The ionic liquid was synthesized according to the following procedure (Scheme 1).

2-Methylmercaptoimidazoline-2 chlorohydrate (MIM-HCl) was synthesized using the method described in Ref. [36]. Forty grams $(0.39 \mathrm{~mol})$ of 2 -imidazolidinethione were suspended in the mixture of methanol $(50 \mathrm{~mL})$ and concentrated hydrochloric acid $(50 \mathrm{~mL})$ with magnetic stirrer. The mixture was heated to reflux for 12 hours. Residual methanol was distilled, and water solution was evaporated. The solid residue was then purified by recrystallization from isopropanol. The obtained product (MIM- $\mathrm{HCl}$ ) has melting point of $160^{\circ} \mathrm{C}$.

${ }^{1} \mathrm{H}$ NMR (300 MHz, DMSO- $\left.d_{6}\right): \delta=2.71\left(\mathrm{t}, 3 \mathrm{H}, \mathrm{CH}_{3}\right), 3.84(\mathrm{~s}, 4 \mathrm{H}$, $\left.\mathrm{CH}_{2}\right), 10.64$ (s, 2H, NH).

The mixture of MIM-HCl (20 g, $0.13 \mathrm{~mol})$, butylamine (9.5 g, $0.13 \mathrm{~mol})$, and isopropanol $(100 \mathrm{~mL})$ was placed into a roundbottomed flask (300 mL) equipped with a reflux condenser and a magnetic stirrer. The mixture was boiled for 6 hours under constant stirring. Methyl mercaptan formed during the reaction was trapped by bubbling through the vessel contained $20 \%$ water solution of potassium hydroxide. After the reaction was completed, isopropanol was distilled at normal pressure. The liquid product of light brown color (BAIM-Cl) was dissolved in methylene chloride $(50 \mathrm{~mL})$, and the solution was filtered to remove nonreacted MIM$\mathrm{HCl}$. Methylene chloride was distilled off. Residual solvents were removed in vacuum 10 mbar at $70{ }^{\circ} \mathrm{C}$ for 12 hours. The yield of BAIM-Cl was $27 \mathrm{~g}$ (72\%).

Ten grams $(0.05 \mathrm{~mol})$ of BAIM-Cl were dissolved in water $(50 \mathrm{~mL})$ under stirring, and the solution of lithium bis(trifluoromethylsulfonyl)imide ( $14.5 \mathrm{~g}, 0.05 \mathrm{~mol}$ ) in $50 \mathrm{~mL}$ of water was added. The formed bottom layer of the ionic liquid BAIM-TFSI was extracted with methylene chloride $(2 \times 50 \mathrm{~mL})$, washed with water $(2 \times 100 \mathrm{~mL})$, and dried under sodium sulfate. Methylene chloride was distilled off, and residual solvent was removed in vacuum 20 mbar at $70{ }^{\circ} \mathrm{C}$ for 8 hours. The viscous liquid of light yellow color was obtained.

NMR spectra of BAIM-TFSI are shown in supplementary file.

${ }^{1} \mathrm{H}$ NMR (400 MHz, DMSO- $\left.d_{6}\right): \delta=0.87\left(\mathrm{t}, 3 \mathrm{H}, \mathrm{CH}_{3}\right), 1.31(\mathrm{~m}, 2 \mathrm{H}$, $\left.\mathrm{CH}_{2}\right), 1.45\left(\mathrm{~m}, 2 \mathrm{H}, \mathrm{CH}_{2}\right), 3.17\left(\mathrm{t}, 2 \mathrm{H}, \mathrm{NH}-\mathrm{CH}_{2}\right), 3.55\left(\mathrm{~s}, 4 \mathrm{H}, 4-\mathrm{CH}_{2}, 5-\right.$ $\mathrm{CH}_{2}$ ), 8.1-8.8 (br s, 3H, NH).

${ }^{19}$ F NMR (188 MHz, DMSO- $\left.d_{6}\right): \delta=-79.92\left(\mathrm{~s}, 6 \mathrm{~F}, \mathrm{CF}_{3}\right)$.

\subsection{Elaboration of PI/BAIM-TFSI composite membranes}

PI solution in methylene chloride was prepared in concentration of $5 \mathrm{~g} / 100 \mathrm{~mL}$. The ionic liquid BAIM-TFSI was added to the polymer solution (30-60 wt\%). The obtained solution was poured onto glass support, and the solvent was allowed to evaporate at room temperature for 24 hours. Thus, transparent films with PIL content of $30,40,50$, and $60 \mathrm{wt} \%$ were prepared. Residual methylene chloride was removed in vacuum 10 mbar at $60{ }^{\circ} \mathrm{C}$ for 12 hours. The thickness of membranes was $50-70 \mu \mathrm{m}$.

Following method was used to prepare composite membranes based on cross-linked PI (Scheme 2) [29,37]. One gram (0.0018 mol) of PI was dissolved in $20 \mathrm{~mL}$ of methylene chloride followed by the addition of 5, 10, and 15 molar percent of Jeffamine D-400 with respect to PI. The solution was stirred for 24 hours at room temperature after that the corresponding amount of BAIM-TFSI was added, and the mixture was further stirred for 2 hours. Composite films PI/Jeffamine/BAIM-TFSI containing $50 \mathrm{wt} \%$ and $60 \mathrm{wt} \%$ of ionic liquid were prepared by casting the solution onto glass support. Control samples of cross-linked PI were prepared without the addition of ionic liquid. The addition of $15 \%$ of Jeffamine resulted in a high content of gel fraction, which precipitated from PI solution. Therefore, only PI samples cross-linked with $5 \%$ and $10 \%$ of Jeffamine were used for the study.

\subsection{Characterization of PI/BAIM-TFSI composites}

The vibrational properties of BAIM-TFSI and its composites with PI were studied using a Vertex-70 Bruker (Germany) Fourier Transform Infrared (FTIR) spectrometer equipped with a deuterated triglycine sulfate (DTGS) detector. The spectrum of pure PIL was obtained from a tablet with KBr. PI/BAIM-TFSI composite films were placed into contact with the single reflection diamond ATR 


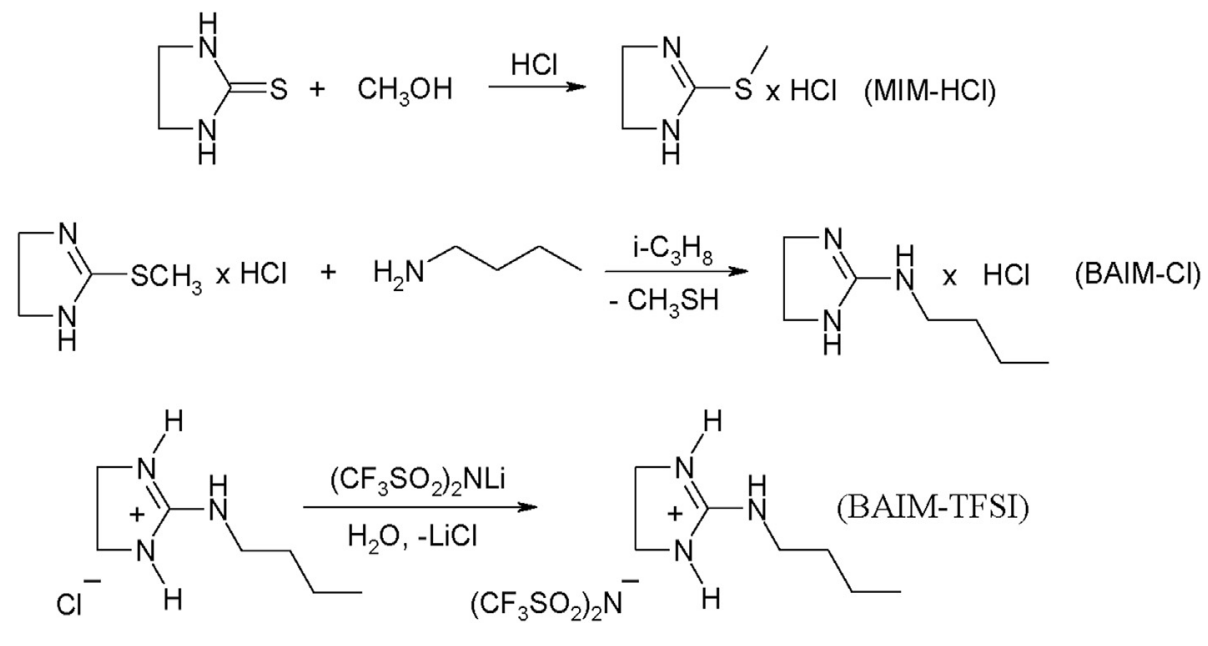

Scheme 1. Synthesis of protic ionic liquid BAIM-TFSI.

(Attenuated Total Reflection) crystal, and the spectra were collected at room temperature over the range $400-4000 \mathrm{~cm}^{-1}$ at a resolution of $1 \mathrm{~cm}^{-1}$.

The mechanical testing of polymer membranes was performed using P-50 universal tensile testing machine (Milaform, Russia) at a deformation rate of $10 \mathrm{~mm} / \mathrm{min}$. Polymer films were cut into specimens with the size of $35 \times 5 \times 0.02 \mathrm{~mm}$. An average tensile strength value was calculated from tensile strength of three individual samples. DMA investigations were carried out on a dynamic mechanical analyzer Q 800 (TA Instruments) in the tension mode at frequency of $10 \mathrm{~Hz}$ and a heating rate of $2.0^{\circ} \mathrm{C} / \mathrm{min}$. The samples for DMA study were cut from Matrimid/BAIM-TFSI composite films and had the size of $12.75 \times 4 \times 0.2 \mathrm{~mm}$. The viscoelastic properties, mechanical loss factor $\left(\tan \delta\right.$ ) and storage modulus $\left(E^{\prime}\right)$, were recorded as a function of temperature.
Thermal gravimetric analysis (TGA) was made using a Q-1500D thermal analyzer. About $100 \mathrm{mg}$ of each sample was heated from $30{ }^{\circ} \mathrm{C}$ to $700{ }^{\circ} \mathrm{C}$ with the heating rate of $10^{\circ} \mathrm{C} / \mathrm{min}$ in air.

The ionic conductivity of ionic liquid and PI/BAIM-TFSI composite membranes was measured with the help of impedance spectrometer Solartron SI 1260 in temperature range from $25^{\circ} \mathrm{C}$ to $160{ }^{\circ} \mathrm{C}$.

\section{Results and discussion}

3.1. Infrared characterization of PI/BAIM-TFSI composite membranes

FTIR is a widely and reliable technique used to characterize very complex mixtures and specific interactions in polymer blend systems by looking into wavenumbers, shape, and intensity of specific
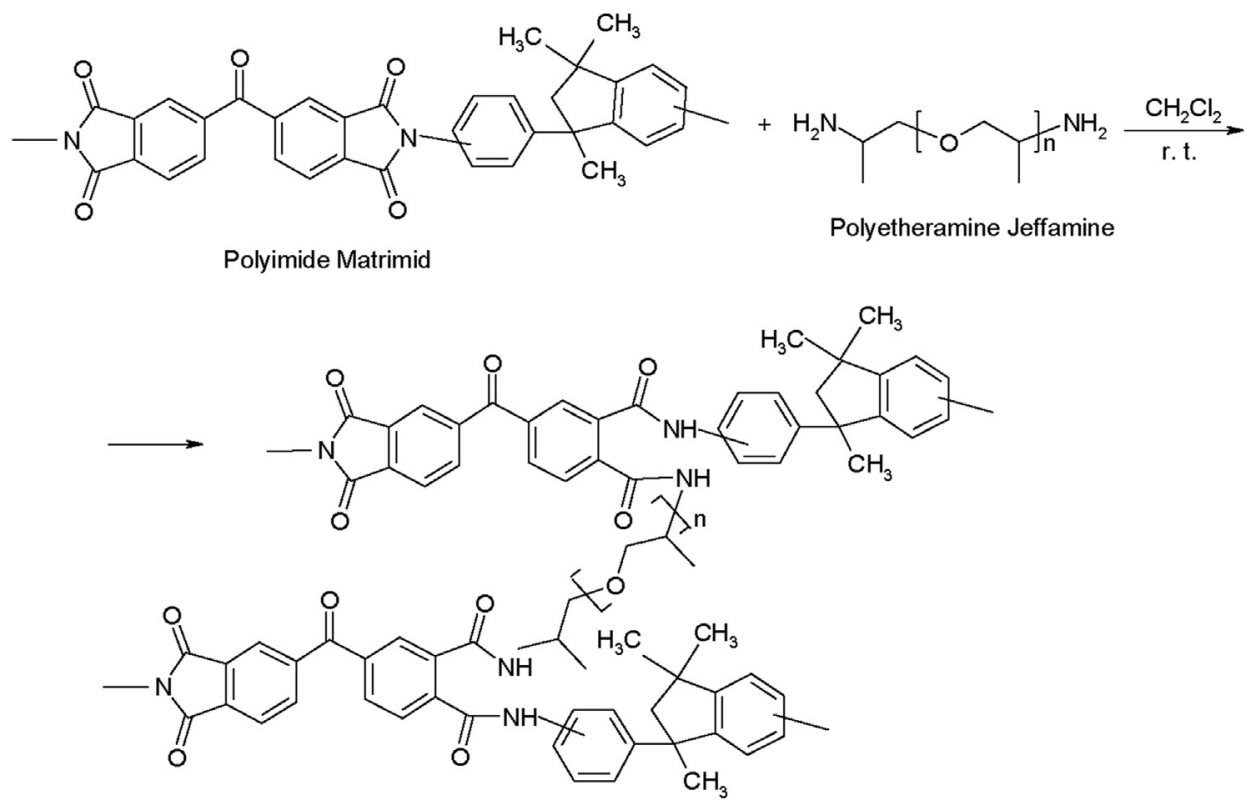

Scheme 2. Cross-linking of polyimide Matrimid with polyetheramine Jeffamine. 


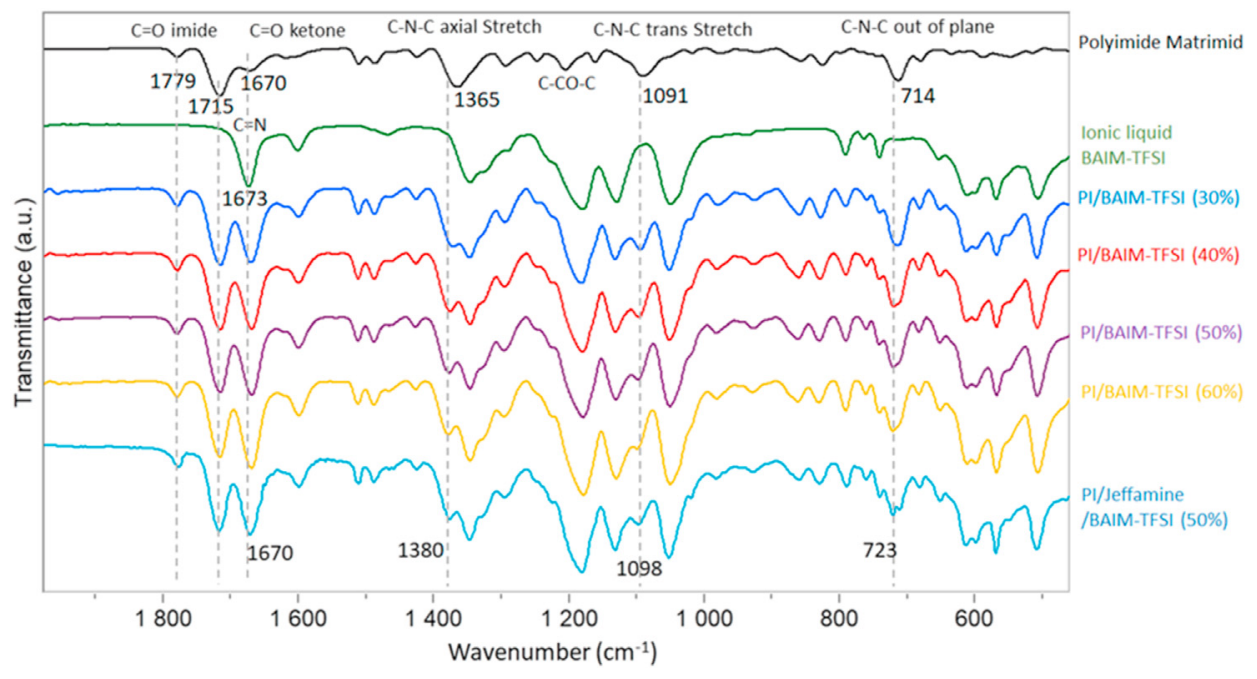

Fig. 1. IR spectra of polyimide Matrimid and its composites with BAIM-TFSI.

functional groups. FTIR-ATR spectra of Matrimid, BAIM-TFSI, and their composites are presented in Fig. 1.

The spectrum of pure Matrimid contains characteristic bands at $1779 \mathrm{~cm}^{-1}$ and $1715 \mathrm{~cm}^{-1}$ assigned to asymmetric and symmetric stretching modes of imide $\mathrm{C}=\mathrm{O}$ groups, respectively, and a small intensity band at $1670 \mathrm{~cm}^{-1}$ is attributed to the stretching vibrations of ketone $C=0$ group [38-40]. The strong bands at 1365 $\mathrm{cm}^{-1}$ and $1091 \mathrm{~cm}^{-1}$ are commonly attributed to the $\mathrm{C}-\mathrm{N}-\mathrm{C}$ axial and trans stretching modes, respectively, and the band at 714 $\mathrm{cm}^{-1}$ - to the out-of-plane bending vibration of the $\mathrm{C}-\mathrm{N}-\mathrm{C}$ group.

For the pure ionic liquid BAIM-TFSI, the main characteristic bands in the range of $2700-4000 \mathrm{~cm}^{-1}$ are the $\mathrm{N}-\mathrm{H}$ stretching mode at $3366 \mathrm{~cm}^{-1}$, the symmetric and asymmetric stretching vibrations of the methylene groups at $2880 \mathrm{~cm}^{-1}$ and $2940 \mathrm{~cm}^{-1}$, and the asymmetric stretching vibrations of the methyl group at 2966 $\mathrm{cm}^{-1}$. In Fig. 1, the strong intensity bands are located at 1673 $\mathrm{cm}^{-1}$ for the $\mathrm{C}=\mathrm{N}$ stretching vibration mode, at $1346 \mathrm{~cm}^{-1}$ and $1129 \mathrm{~cm}^{-1}$ for the $\mathrm{SO}_{2}$ antisymmetric and symmetric stretching modes and at $1180 \mathrm{~cm}^{-1}$ and $1050 \mathrm{~cm}^{-1}$ for $\mathrm{CF}_{3}$ antisymmetric stretching and the $\mathrm{C}-\mathrm{C}$ stretching modes, respectively [41].

For PI/BAIM-TFSI composite films, no significant change was observed either in peak position or intensity of the bands corresponding to vibrations of both ketone and imide $\mathrm{C}=\mathrm{O}$ groups (Fig. 1). This may indicate the absence of hydrogen bonding between $\mathrm{N}-\mathrm{H}$ groups of BAIM-TFSI and $\mathrm{C}=\mathrm{O}$ groups of Matrimid. This result is likely owing to the self-association of PI macromolecules because of the formation of charge-transfer complex between carbonyl groups and imide nitrogen [42] (Scheme 2). On the other hand, specific interactions between aromatic rings with their $\pi$ electronic sextet lead to parallel and planar orientation of individual chains to each other. The increased inter-chain attractive forces can thus induce a better packing of the polymer chains, leading to an increase in the rigidity of the composite and, therefore, in the glass transition temperature.

With the introduction of BAIM-TFSI, the IR spectra of composite films revealed that the $\mathrm{C}-\mathrm{N}-\mathrm{C}$ vibrational modes of imide cycle were shifted to higher wavenumber: from 1365 to $1380 \mathrm{~cm}^{-1}$, from 1091 to $1098 \mathrm{~cm}^{-1}$, and from 714 to $723 \mathrm{~cm}^{-1}$ (Fig. 1). In addition, a shift of the $\mathrm{C}=\mathrm{N}$ vibrations of the pure ionic liquid was observed toward lower wavenumber. According to these results, it can be suggested that $\pi-\pi$ interaction between imidazolinium cation and imide cycle of Matrimid occurs (Scheme 3). Such physicochemical interactions can affect both the compatibility of BAIM-TFSI with polymer matrix and the self-association of PI macromolecules.

\subsection{Mechanical and thermal analysis of PI/BAIM-TFSI composites}

The results of tensile testing of PI-based composite films containing different amount of ionic liquid are summarized in Table 1. The obtained results clearly indicate that PI/BAIM-TFSI composites have mechanical properties similar to the neat polymer and this for ionic liquid content up to $50 \mathrm{wt} \%$. The low values of elongation at break for all composites confirm the high material rigidity. For PI/ BAIM-TFSI (60\%) films, the drop of tensile strength by more than $50 \%$ was observed. It is also interesting to note that the introduction of $30 \%$ of ionic liquid leads to a significant improvement of the tensile strength of Matrimid. PI films cross-linked with $10 \mathrm{~mol} \%$ of polyetheramine Jeffamine also showed significantly improved tensile strength compared with neat polymer (Table 1). However, cross-linked PI containing $50 \%$ of ionic liquid has similar mechanical properties as PI/BAIM-TFSI (50\%). The prepared dense composite membranes have much better tensile strength (at least $50 \%-$ $70 \%$ more) compared with PEMs based on sulfonated PI/PIL [24] or porous Matrimid/PIL [27].

DMA study was further performed to assess the mechanical response of PI/BAIM-TFSI membranes to higher temperatures. PI Matrimid has high storage modulus $E^{\prime}$ (1320-630 MPa; Fig. 2a, curve 1) and low values of $\tan \delta$ (Fig. 2b, curve 1 ) in the temperature range $20-300{ }^{\circ} \mathrm{C}$, indicating its excellent elastic properties for the use as polymer matrix for PEM. PI/BAIM-TFSI composite membranes with ionic liquid content up to $50 \%$ showed significantly increased $E^{\prime}$ values at room temperature, compared with neat polymer (Fig. 2a, curves 2-4, Table 2). Moreover, PI membrane containing $30 \%$ of BAIM-TFSI demonstrated improved elastic properties at elevated temperatures up to $150{ }^{\circ} \mathrm{C}$ (Fig. 2a, curves 1 and 2). At a higher ionic liquid content of $40 \%$ and $50 \%$, this effect was also observed but in narrowed temperature range (Fig. 2a, curves 3 and 4). Probably, increased stiffness of PI/BAIM-TFSI composites is caused by the increasing of the packing density of PI macromolecules below glass transition temperature because of their physicochemical interaction with 2-butylaminoimidazolinium cation of ionic liquid (Scheme 2). However, the increase of BAIM-TFSI content in PI films leads to noticeable reduction of temperature at which drop in storage modulus begins (Fig. 2a, curves 2-5). This is also 


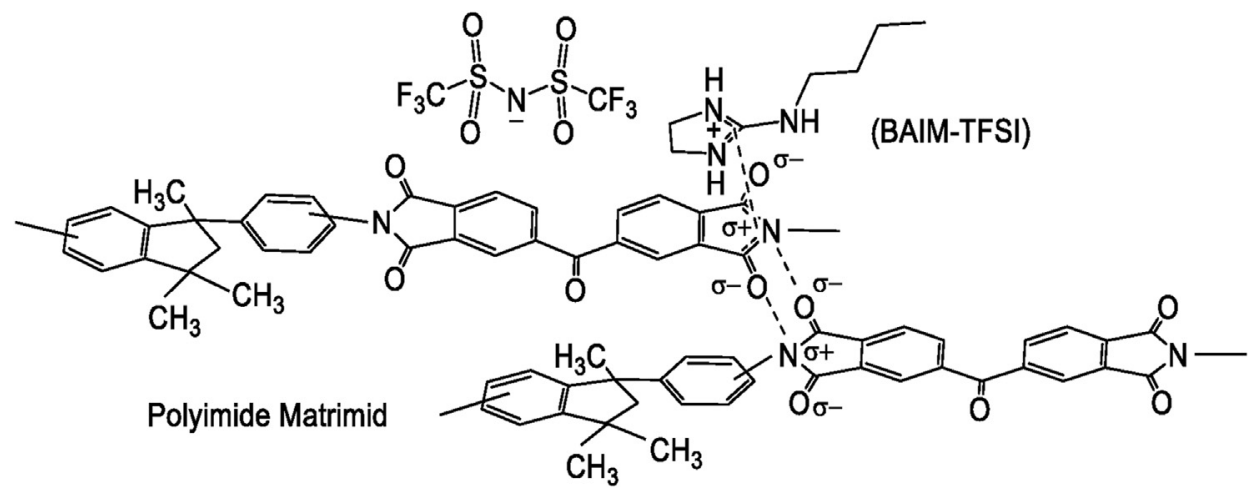

Scheme 3. Possible physicochemical interactions between PI and protic ionic liquid.

Table 1

Mechanical properties of PI/BAIM-TFSI composite films.

\begin{tabular}{lll}
\hline Sample & Tensile strength, MPa & Elongation at break, \% \\
\hline PI & $37.0 \pm 1.0$ & $7.2 \pm 0.5$ \\
PI/BAIM-TFSI (30\%) & $72.5 \pm 1.5$ & $8.4 \pm 1.5$ \\
PI/BAIM-TFSI (40\%) & $36.5 \pm 1.0$ & $8.0 \pm 0.5$ \\
PI/BAIM-TFSI (50\%) & $32.6 \pm 2.0$ & $12.0 \pm 2.5$ \\
PI/BAIM-TFSI (60\%) & $16.0 \pm 2.0$ & $12.5 \pm 1.5$ \\
PI/Jeffamine (10\% mol) & $69.2 \pm 2.0$ & $9.3 \pm 2.5$ \\
PI/Jeffamine/BAIM-TFSI (50\%) & $35.0 \pm 1.0$ & $7.5 \pm 2.5$ \\
PI/Jeffamine/BAIM-TFSI (60\%) & $25.0 \pm 2.0$ & $8.0 \pm 1.5$ \\
\hline
\end{tabular}
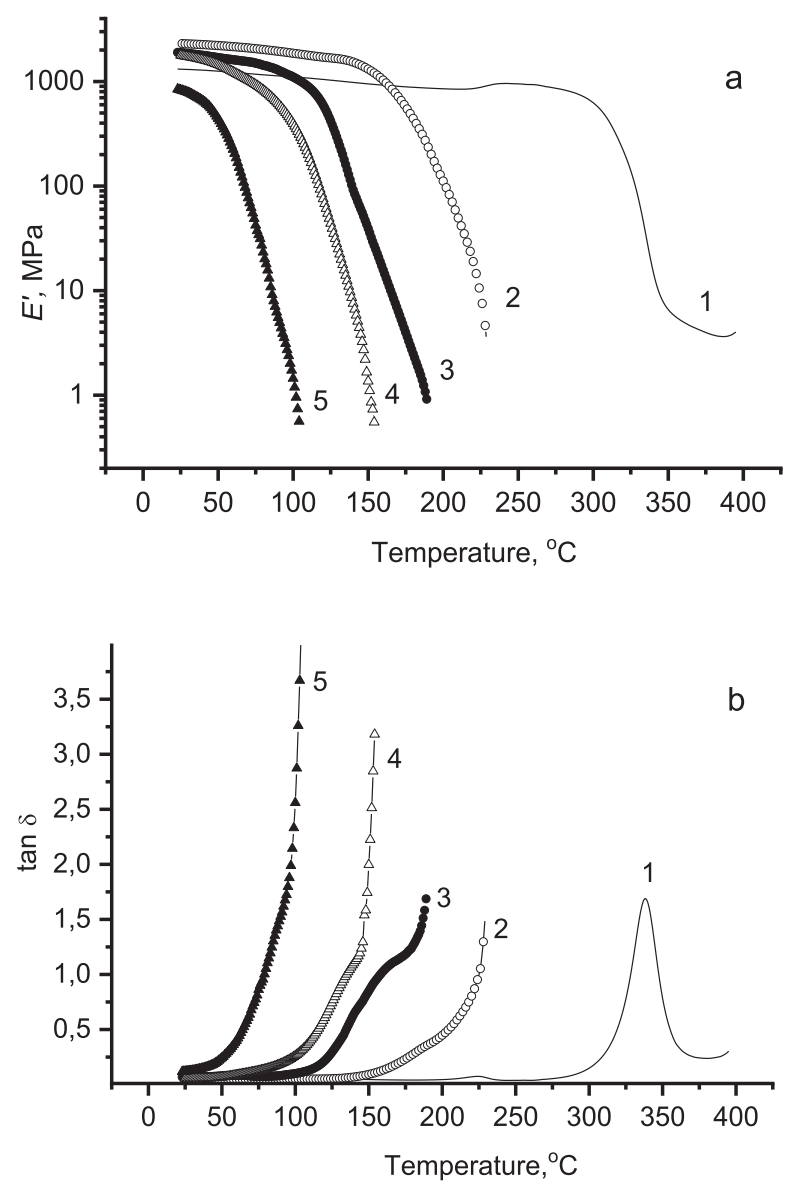

Fig. 2. DMA curves of $E^{\prime}(a)$ and $\tan \delta(b)$ : 1, polyimide Matrimid; 2, PI/BAIM-TFSI (30\%); 3, PI/BAIM-TFSI (40\%); 4, PI/BAIM-TFSI (50\%); 5, PI/BAIM-TFSI (60\%). accompanied by a sharp increase in $\tan \delta$ value (Fig. 2b, curves 2-5). These effects indicate a plasticizing effect of the ionic liquid on PI. Although significant reduction of storage modulus was observed for PI/BAIM-TFSI (40\%) membrane above $120{ }^{\circ} \mathrm{C}$ (Fig. 2a, curve 3), this membrane still has $E^{\prime}$ value comparable to those reported for commercial Nafion membranes [43-45]. Further increase of ionic liquid content leads to a narrowing of the temperature range of acceptable mechanical properties to $120{ }^{\circ} \mathrm{C}$ with $50 \%$ content BAIM-TFSI and to $70{ }^{\circ} \mathrm{C}$ with $60 \%$ BAIMTFSI (Fig. 2a, curves 4 and 5, Table 2).

The glass transition temperature $\left(T_{\mathrm{g}}\right)$ of neat Matrimid determined by the position of the maximum of the loss factor $\tan \delta$ (Fig. 2b, curve 1 ) was found to be $335^{\circ} \mathrm{C}$, indicating a high stiffness of polymer macromolecules. However, PI/BAIM-TFSI composites do not demonstrate distinct relaxation maximum on the temperature dependence of $\tan \delta$ (Fig. 2b, curves $2-5$ ). Such a result can be explained by high plasticization effect of ionic liquid. Indeed, viscous flow in the material can develop so quickly that the glass transition does not have time to be fixed. Thus, the temperature at which $\tan \delta$ begins to rise can be defined as glass transition onset ( $T_{\text {onset }}$ ).

Previous studies of polymer electrolyte membranes based on sulfonated PIs and PILs have shown that the ionic liquid content of at least $50 \%-60 \%$ is required to reach sufficient level of ionic conductivity at elevated temperatures $[24,26,28]$. Therefore, we have tried to improve elastic properties of PI/BAIM-TFSI membranes with the same ionic liquid content by using partially cross-linked PI as polymer matrix. As one can see from Fig. 3a (curve 1) and Table 2, cross-linking of PI with $10 \mathrm{~mol} \%$ of polyetheramine Jeffamine D-400 significantly improved its storage modulus both at room and elevated temperatures. This effect was not observed for lower content ( $5 \mathrm{~mol} \%$ ) of cross-linking agent (not shown). It should be noted that the glass transition temperature of $\mathrm{PI} / \mathrm{Jeffamine}$ is $30^{\circ} \mathrm{C}$ lower compared with neat PI (Table 2). The opening of imide cycles in PI macromolecules after their partial cross-linking with flexible chains of Jeffamine can lead to an increase of the free volume in the polymer matrix (Scheme 2). Therefore, the mobility of molecular chains increases, resulting in a reduction of $T_{\mathrm{g}}$. At the same time, the presence of intermolecular cross-linking increases the resistance of material to deformation.

Similar to PI/BAIM-TFSI composites, there is no distinct relaxation maximum on $\tan \delta=\mathrm{f}(\mathrm{T})$ dependences for $\mathrm{PI} /$ Jeffamine/BAIM-TFSI films (Fig. 3b, curves 2,3 ). $T_{\text {onset }}$ value was also found to be significantly reduced with increasing ionic liquid content, indicating a strong plasticizing effect of BAIMTFSI (Fig. 3, Table 2). However, in contrast to PI/BAIM-TFSI (50\%) composite, PI/Jeffamine/BAIM-TFSI (50\%) membrane showed reasonable $E^{\prime}$ value of $300 \mathrm{MPa}$ at $130{ }^{\circ} \mathrm{C}$ (Table 2), which is comparable with those reported for commercial proton- 
Table 2

Viscoelastic characteristics of PI/BAIM-TFSI membranes.

\begin{tabular}{|c|c|c|c|c|c|c|}
\hline Sample & $T_{\mathrm{g}},{ }^{\circ} \mathrm{C}$ & $T_{\text {onset }},{ }^{\circ} \mathrm{C}$ & $E_{\mathrm{T}}^{\prime}=25^{\circ} \mathrm{C}, \mathrm{MPa}$ & $E_{T=120{ }^{\circ} \mathrm{C}, \mathrm{MPa}}^{\prime}$ & $E^{\prime}{ }_{T=130}^{\circ} \mathrm{C}, \mathrm{MPa}$ & $E^{\prime}{ }_{T=140{ }^{\circ} \mathrm{C}, \mathrm{MPa}}$ \\
\hline PI & 335 & 300 & 1320 & 1050 & 1015 & 980 \\
\hline PI/BAIM-TFSI (30\%) & - & 165 & 2304 & 1710 & 1652 & 1535 \\
\hline PI/BAIM-TFSI (40\%) & - & 120 & 1885 & 596 & 268 & 92 \\
\hline PI/BAIM-TFSI (50\%) & - & 88 & 1780 & 75 & 25 & 7.5 \\
\hline PI/BAIM-TFSI (60\%) & - & 50 & 828 & - & - & - \\
\hline PI/Jeffamine (10 mol\%) & 305 & 265 & 2087 & 1621 & 1573 & 1528 \\
\hline PI/Jeffamine/BAIM-TFSI (50\%) & - & 130 & 1633 & 450 & 300 & 156 \\
\hline PI/Jeffamine/BAIM-TFSI (60\%) & - & 65 & 1327 & 8.7 & - & - \\
\hline
\end{tabular}

conducting membranes such as Nafion $[43,45]$ or phosphoric acid impregnated PBI [46]. Further increase of ionic liquid content in cross-linked PI-based composite led to soft material with unsatisfactory elastic behavior (Fig. 3a, curve 3, Table 2). Thus, we limited maximum ionic liquid content to $50 \mathrm{wt} \%$ for studying the conductivity of PI/BAIM-TFSI membranes.

According to TGA data, BAIM-TFSI ionic liquid has the thermal degradation point (i.e., $5 \%$ weight loss) of $350{ }^{\circ} \mathrm{C}$, with maximum rate at $456{ }^{\circ} \mathrm{C}$ (Fig. 4, curve 1, Table 3) that indicates sufficient thermal stability for high-temperature fuel cell applications. PI Matrimid has outstanding thermal properties being stable to at least $455^{\circ} \mathrm{C}$ with maximum degradation rate at $595^{\circ} \mathrm{C}$ (Fig. 4, curve 2). PI/BAIM-TFSI composites also showed high thermal stability (Fig. 4, curves 3-6) with thermal degradation points in the
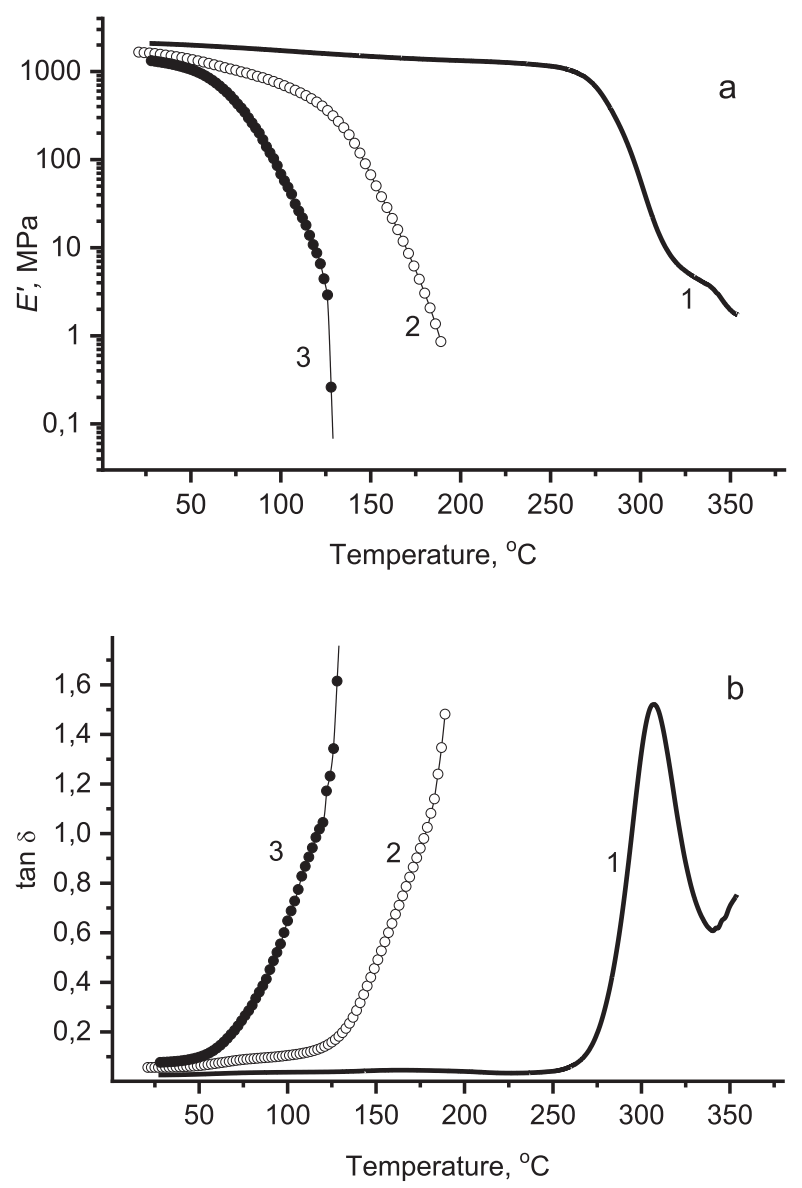

Fig. 3. DMA curves of $E^{\prime}(a)$ and tan $\delta$ (b): $1, \mathrm{PI} / \mathrm{Jeffamine}(10 \mathrm{~mol} \%) ; 2, \mathrm{PI} / \mathrm{Jeffamine} /$ BAIM-TFSI (50\%); 3, PI/Jeffamine/BAIM-TFSI (60\%). temperature range $377^{\circ} \mathrm{C}-397^{\circ} \mathrm{C}$, which were noticeably higher compared with pure PIL (Table 3 ).

PI cross-linked with polyetheramine Jeffamine began to decompose at $318{ }^{\circ} \mathrm{C}$, thus showing significantly reduced thermal stability than neat polymer (Fig. 5a). However, composite membranes based on cross-linked PI and BAIM-TFSI were found to have similar thermal properties as PI/BAIM-TFSI membranes (Fig. 5b, Table 3).

\subsection{Ionic conductivity of PI/BAIM-TFSI composite membranes}

The ionic conductivity of pure ionic liquid and PI/BAIM-TFSI composite membranes was measured in the temperature range of $25-160{ }^{\circ} \mathrm{C}$ (Fig. 6). The conductivity of BAIM-TFSI was found to be $5 \times 10^{-3} \mathrm{~S} / \mathrm{cm}$ at room temperature. This value increased by one order of magnitude below $100{ }^{\circ} \mathrm{C}$ (Table 4), reaching the value similar to that of other hydrophobic PILs with TFSI anion [16]. All studied PI/BAIM-TFSI membranes showed poor ionic conductivity at room temperature-from $3.1 \times 10^{-9} \mathrm{~S} / \mathrm{cm}$ to $3.1 \times 10^{-6} \mathrm{~S} / \mathrm{cm}$. This is probably caused by low free volume of the system, which creates barriers for efficient proton transfer. At elevated temperatures, the conductivity of composite films significantly increased by three to five orders of magnitude, depending on ionic liquid content (Fig. 6, curves 2-4, Table 4). This may be explained by enhanced free ionic mobility of BAIM-TFSI in the membrane matrix [16,19]. Moreover, segmental motion of PI macromolecules because of plasticization effect of ionic liquid at temperatures above $100{ }^{\circ} \mathrm{C}$ (Table 2) may also promote the formation of well-developed ionic channels. Accordingly, the minimal level of ionic conductivity $\left(10^{-3} \mathrm{~S} / \mathrm{cm}\right)$ required for PEM was reached for PI/BAIM-TFSI $(40 \%)$ membrane at $145{ }^{\circ} \mathrm{C}$ and for PI/BAIM-TFSI (50\%) membrane at

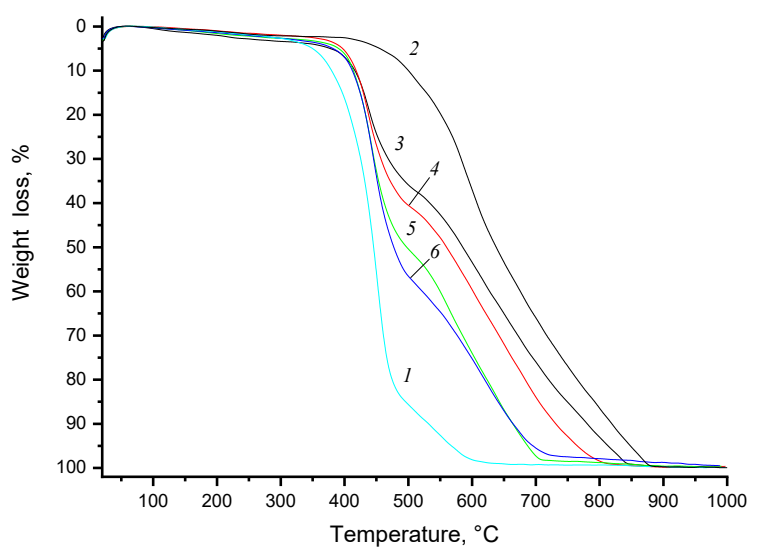

Fig. 4. TGA curves of BAIM-TFSI (1), PI (2), and PI/BAIM-TFSI with different ionic liquid content: $30 \%(3), 40 \%(4), 50 \%(5)$, and $60 \%(6)$. 
Table 3

TGA data for BAIM-TFSI and its composites with polyimide Matrimid.

\begin{tabular}{|c|c|c|c|c|}
\hline Sample & $\mathrm{T}_{\Delta \mathrm{m}=5 \%},{ }^{\circ} \mathrm{C}$ & $\mathrm{T}_{\Delta \mathrm{m}=10 \%},{ }^{\circ} \mathrm{C}$ & $\mathrm{T}_{\Delta \mathrm{m}=20 \%},{ }^{\circ} \mathrm{C}$ & $\mathrm{T}_{\Delta \mathrm{m}=50 \%},{ }^{\circ} \mathrm{C}$ \\
\hline BAIM-TFSI & 350 & 380 & 408 & 445 \\
\hline PI & 455 & 500 & 551 & 638 \\
\hline PI/BAIM-TFSI (30\%) & 377 & 416 & 440 & 585 \\
\hline PI/BAIM-TFSI (40\%) & 397 & 418 & 438 & 560 \\
\hline PI/BAIM-TFSI (50\%) & 391 & 414 & 433 & 497 \\
\hline PI/BAIM-TFSI (60\%) & 382 & 412 & 433 & 477 \\
\hline PI/Jeffamine (10 mol\%) & 318 & 426 & 523 & 641 \\
\hline PI/Jeffamine/BAIM-TFSI (50\%) & 370 & 417 & 441 & 525 \\
\hline PI/Jeffamine/BAIM-TFSI (60\%) & 379 & 409 & 429 & 478 \\
\hline
\end{tabular}

$120{ }^{\circ} \mathrm{C}$ (Fig. 6, curves 3 and 4, Table 4). The composite membrane based on cross-linked PI and BAIM-TFSI (50\%) showed noticeably higher conductivity than PI/BAIM-TFSI (50\%). Thus, the conductivity reached the level of $10^{-3} \mathrm{~S} / \mathrm{cm}$ at $60{ }^{\circ} \mathrm{C}$ and increased by one order of magnitude at $120^{\circ} \mathrm{C}$ (Fig. 6, curve 5, Table 4). It is reasonable to assume that PI matrix, cross-linked with bulk and flexible Jeffamine molecules, has higher free volume compared with the linear PI matrix, thus promoting the formation of proton transfer channels.

As previously described, two types of charge transport mechanism in PILs exist: vehicle (molecular diffusion) and Grotthuss-type (proton migration in the hydrogen-bonded networks). Imidazolinium cation of BAIM-TFSI contains three exchangeable protons, which may ensure efficient proton hopping conduction mechanism. The last one involves thermal activation and follows Arrhenius law as a function of temperature:
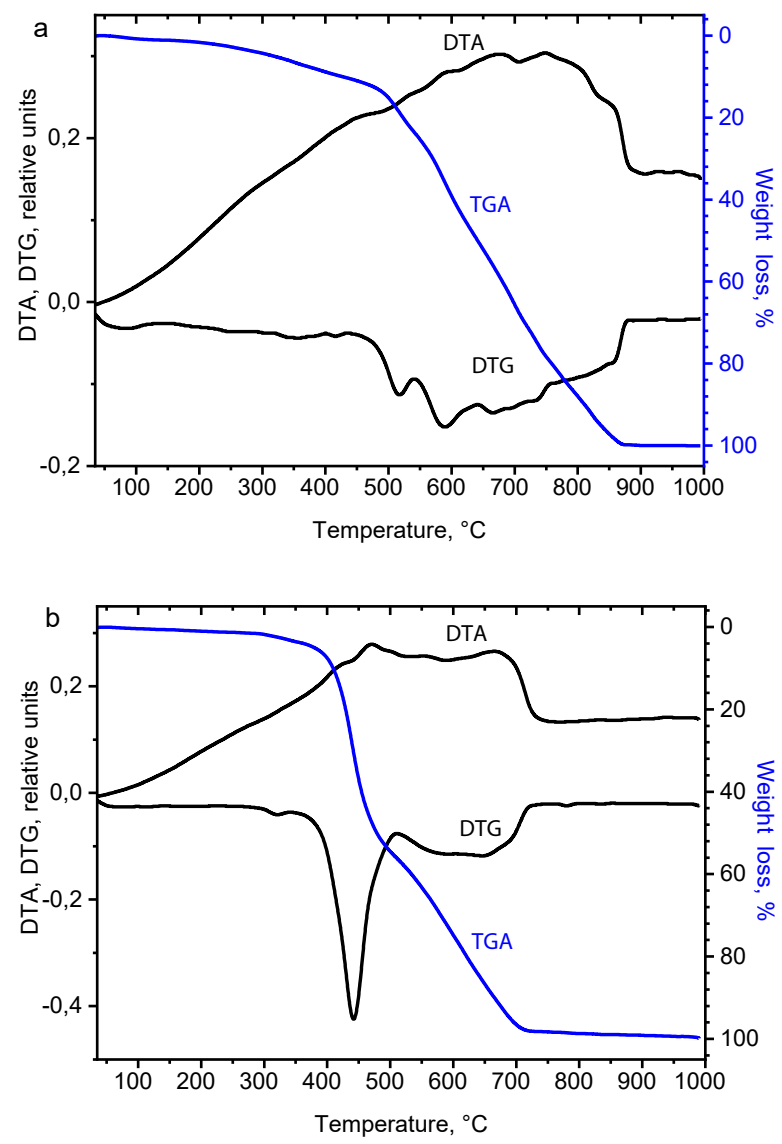

Fig. 5. TGA curves of polyimide Matrimid cross-linked with polyetheramine Jeffamine (a) and PI/Jeffamine/BAIM-TFSI (50\%) composite (b). $\ln \sigma=-\mathrm{E}_{\mathrm{a}} / \mathrm{RT}+\ln \sigma_{0}$

where $\sigma_{0}$ is the maximum conductivity at infinite temperature (S/ $\mathrm{cm}), E_{a}$ is the activation energy $(\mathrm{kJ} / \mathrm{mol})$, which indicates the energy needed for an ion to jump to a free hole, $R$ is the universal gas constant $(8.314 \mathrm{~J} /(\mathrm{mol} \cdot \mathrm{K})$, and $\mathrm{T}$ is the absolute temperature $(\mathrm{K})$.

Thus, the activation energy for conductivity characterizes the difficulty level of ions migration under the electric field. In the Arrhenius diagram (Fig. 7), temperature dependence of ionic conductivity $(\ln \sigma$ vs $1000 / \mathrm{T})$ is linear in the temperature range 60 ${ }^{\circ} \mathrm{C}-130{ }^{\circ} \mathrm{C}$ for both pure BAIM-TFSI and PI/BAIM-TFSI membranes. The activation energy $E_{a}$ calculated from the slope value (Fig. 7, line 1 ) is $22 \mathrm{~kJ} / \mathrm{mol}$ for pure ionic liquid. This value is higher compared with other reported guanidinium-based PILs-1-butylguanidinium tetrafluoroborate $\left(E_{a}=17 \mathrm{~kJ} / \mathrm{mol}\right)$ [35] and guanidinium nonaflate $\left(E_{a}=19 \mathrm{~kJ} / \mathrm{mol}\right)$ [47]. This indicates less mobility in proton transfer of the bulk 1-butylaminoimidazolinium cation with lower content of exchangeable protons, compared with guanidinium-based ionic liquids.

The Arrhenius plots for PI/BAIM-TFSI membranes reveal steeper slopes compared with the ionic liquid (Fig. 7, lines 2-5), which indicates significantly higher activation energy for ionic conductivity. Thus, calculated $E_{a}$ values were found to be 113 , 80 , and $57 \mathrm{~kJ} / \mathrm{mol}$ for PI/BAIM-TFSI composites containing 30\%, $40 \%$, and $50 \%$ of ionic liquid, respectively. The Grotthuss-type mechanism of proton conduction is known to involve activation energies below $0.4 \mathrm{eV}(<38.5 \mathrm{~kJ} / \mathrm{mol})$, whereas the transport of larger ionic species (vehicle mechanism) requires higher energy $\left(E_{a}>0.4 \mathrm{eV}\right)$ [48]. Thus, the obtained data clearly indicate that the proton transport in PI/BAIM-TFSI membranes is realized mainly by vehicle mechanism. The content of $50 \%$ of ionic liquid

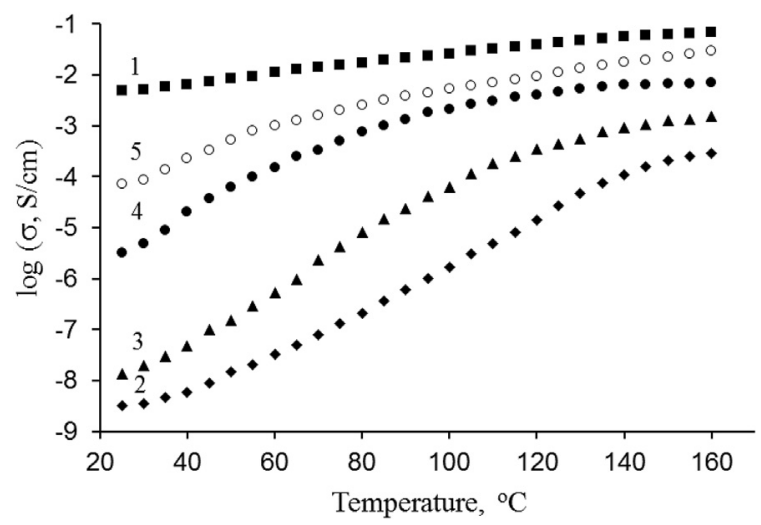

Fig. 6. Ionic conductivity (at frequency of $1 \mathrm{kHz}$ ) as a function of temperature (heating process) for BAIM-TFSI (1), PI/BAIM-TFSI composite membranes containing 30\% BAIMTFSI (2), 40\% BAIM-TFSI (3), 50\% BAIM-TFSI (4), and PI/Jeffamine/BAIM-TFSI (50\%) (5) membranes. 
Table 4

Ionic conductivity of protic ionic liquid and PI/BAIM-TFSI composite membranes as a function of temperature.

\begin{tabular}{|c|c|c|c|c|}
\hline \multirow[t]{2}{*}{ Sample } & \multicolumn{4}{|l|}{$\sigma, \mathrm{S} / \mathrm{cm}$} \\
\hline & $25^{\circ} \mathrm{C}$ & $120^{\circ} \mathrm{C}$ & $130{ }^{\circ} \mathrm{C}$ & $140{ }^{\circ} \mathrm{C}$ \\
\hline BAIM-TFSI & $5.0 \times 10^{-3}$ & $4.0 \times 10^{-2}$ & $4.6 \times 10^{-2}$ & $5.6 \times 10^{-2}$ \\
\hline PI/BAIM-TFSI (30 wt\%) & $3.1 \times 10^{-9}$ & $1.6 \times 10^{-5}$ & $5.0 \times 10^{-5}$ & $1.1 \times 10^{-4}$ \\
\hline PI/BAIM-TFSI (40 wt\%) & $1.6 \times 10^{-8}$ & $3.5 \times 10^{-4}$ & $5.0 \times 10^{-4}$ & $8.0 \times 10^{-4}$ \\
\hline PI/BAIM-TFSI (50 wt\%) & $3.1 \times 10^{-6}$ & $4.0 \times 10^{-3}$ & $5.3 \times 10^{-3}$ & $6.3 \times 10^{-3}$ \\
\hline PI/Jeffamine/BAIM-TFSI (50\%) & $2.7 \times 10^{-5}$ & $7.9 \times 10^{-3}$ & $1.1 \times 10^{-2}$ & $1.6 \times 10^{-2}$ \\
\hline
\end{tabular}

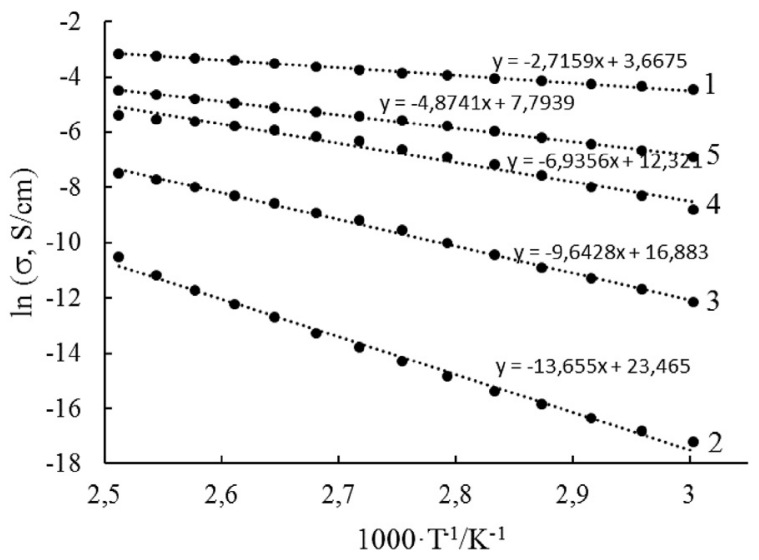

Fig. 7. Arrhenius plots of ionic conductivity for BAIM-TFSI (1), PI/BAIM-TFSI membrane containing 30\% BAIM-TFSI (2), 40\% BAIM-TFSI (3), 50\% BAIM-TFSI (4), and PI/Jeffamine/ BAIM-TFSI (50\%) membrane (5).

in dielectric PI matrix is probably insufficient to realize the hopping mechanism of proton transport, which was found to dominate in commercial PBI and Nafion membranes impregnated with commonly used PILs TEA-TF or [dema][TfO] [49,50]. It can be explained by the fact that both PBI or Nafion polymer matrix and PIL participate in the proton transport, whereas in PI/BAIM-TFSI membranes, the polymer matrix does not contain proton-conducting sites. However, PI/Jeffamine/BAIM-TFSI (50\%) membrane was found to have an $E_{a}$ value of $40 \mathrm{~kJ} / \mathrm{mol}$, significantly lower than the value found for the PI/BAIM-TFSI (50\%) composite (Fig. 7, lines 4, 5). In this system, the Grotthuss-type mechanism of proton conduction may be expected to occur. Similar calculated values of activation energy of ionic conductivity $(\sim 40 \mathrm{~kJ} / \mathrm{mol})$ have been reported for PBI/[dema][TfO] [49] and SPI/2-undecylimidazole [8] composites in which proton transfer is known to be realized mainly by hopping mechanism. It is interesting to note that the ionic conductivity of $\mathrm{PI} /$ Jeffamine/BAIM-TFSI (50\%) membrane above $120{ }^{\circ} \mathrm{C}$ (Fig. 6, curve 5 , Table 4 ) is similar to those for composite membranes based on SPIs containing 50\% of PIL [24,26]. This indicates the possibility of manufacturing proton-conducting membranes based on PIs without the use of an expensive stage of their sulfonation.

\section{Conclusions}

New hydrophobic protic ionic liquid comprising cyclic guanidinium cation, BAIM-TFSI, has been synthesized. The ionic liquid combines both high thermal stability (to at least $350^{\circ} \mathrm{C}$ ) and ionic conductivity $\left(5.6 \times 10^{-2} \mathrm{~S} / \mathrm{cm}\right.$ at $\left.140^{\circ} \mathrm{C}\right)$. It has excellent compatibility with commercial PI Matrimid, allowing the preparation of composite films containing from 30 to $60 \mathrm{wt} \%$ of BAIM-TFSI by casting from methylene chloride solutions. TGA results indicate good thermal stability of PI/BAIM-TFSI composites having thermal degradation points in the range of $377^{\circ} \mathrm{C}-397^{\circ} \mathrm{C}$. According to the results of mechanical testing, the addition of BAIM-TFSI up to $50 \%$ in PI films does not cause a noticeable deterioration of tensile strength of the polymer. Moreover, DMA analysis revealed significantly improved viscoelastic properties of PI/BAIM-TFSI membranes at room temperature compared with Matrimid. At lowest ionic liquid content of $30 \%$, the tensile strength and storage modulus $E^{\prime}$ of the composite were found to increase by $94 \%$ and $74 \%$, respectively. This is probably caused by denser packing of PI macromolecules as a result of their physicochemical interactions with BAIM-TFSI. However, significant reduction of $E^{\prime}$ value for PI/BAIM-TFSI films was observed above $100{ }^{\circ} \mathrm{C}$ because of plasticization effect of the ionic liquid on polymer matrix. The results of electrochemical impedance study of PI/BAIM-TFSI membranes have shown that the minimal level of ionic conductivity $\left(10^{-3} \mathrm{~S} / \mathrm{cm}\right)$ required for PEM can be reached for PI/BAIM-TFSI (40\%) at $145^{\circ} \mathrm{C}$ or for PI/BAIM-TFSI (50\%) at $120{ }^{\circ} \mathrm{C}$.

To improve elastic properties of composite membrane, PI was cross-linked with polyetheramine Jeffamine D-400 (10 mol\%) in methylene chloride solution at room temperature. This approach allowed to prepare PI/Jeffamine/BAIM-TFSI (50\%) membrane having $E^{\prime}$ value of $300 \mathrm{MPa}$ at $130{ }^{\circ} \mathrm{C}$, in contrast to PI/BAIM-TFSI (50\%) composite, which has storage modulus of $25 \mathrm{MPa}$. The ionic conductivity of composite membrane reached the level of $10^{-2} \mathrm{~S} / \mathrm{cm}$ at $130{ }^{\circ} \mathrm{C}$ that makes it potentially available for the use in mediumtemperature fuel cells operating in water-free conditions. The activation energy $E_{a}$ values calculated from the Arrhenius plot for pure ionic liquid BAIM-TFSI as well as for PI/Jeffamine/BAIM-TFSI (50\%) membrane were found to be $22 \mathrm{~kJ} / \mathrm{mol}$ and $40 \mathrm{~kJ} / \mathrm{mol}$, respectively. On the basis of these data, one can conclude that the proton transport in both ionic liquid and PI-based composite membrane is dominated by Grotthuss-type (hopping) mechanism. It is also important to note that PI/Jeffamine/BAIM-TFSI membrane showed similar ionic conductivity at elevated temperatures as previously reported PEMs based on sulfonated aromatic PIs and PILs. This approach, based on simple and inexpensive preparation methods, opens up really promising perspectives to develop proton-conducting membranes for fuel cell applications based on commercial PI Matrimid. Additional research is nevertheless underway to improve room temperature conductivity of the elaborated membranes, which is insufficient for normal operation of fuel cells below $100{ }^{\circ} \mathrm{C}$.

\section{Authors' contributions}

S.R. synthesized ionic liquid and cross-linked polyimide and wrote the article. J.-F.B. performed infrared analysis and wrote the article. S.M. performed electrophysical investigations. O.T. prepared composite membranes. N.B. performed dynamic mechanical analysis. Tetiana T.C. performed thermal investigations. M.F. analyzed the data. K.F. conceived and designed the experiments and analyzed the data 


\section{Declaration of competing interest}

The authors declare that they have no known competing financial interests or personal relationships that could have appeared to influence the work reported in this paper.

\section{Acknowledgments}

The authors are grateful to Huntsman society (Switzerland) for free giving of Matrimid 5218 powder.

\section{Appendix A. Supplementary data}

Supplementary data to this article can be found online at https://doi.org/10.1016/j.mtchem.2021.100453.

\section{References}

[1] Y. Wang, K.S. Chen, J. Mishler, S.C. Cho, X. Cordobes Adroher, A review of polymer electrolyte membrane fuel cells: technology, applications, and needs on fundamental research, Appl. Energy 88 (2011) 981-1007.

[2] K.A. Mauritz, R.B. Moore, State of understanding of Nafion, Chem. Rev. 104 (2004) 4535-5458.

[3] E. Quartarone, S. Angioni, P. Mustarelli, Polymer and composite membranes for proton conducting, high-temperature fuel cells: a critical review, Materials 10 (2017) 687-703.

[4] A.-C. Dupuis, Proton exchange membranes for fuel cells operated at medium temperatures: materials and experimental techniques, Prog. Mater. Sci. 56 (2011) 289-327.

[5] Q. Li, J.O. Jensen, R.F. Savinell, N.J. Bjerrum, High temperature proton exchange membranes based on polybenzimidazoles for fuel cells, Prog. Polym. Sci. 34 (2009) 449-477.

[6] A. Chandan, M. Hattenberger, A. El-kharouf, S. Du, A. Dhir, V. Self, B.G. Pollet, A. Ingram, W. Bujalski, High-temperature (HAT) polymer electrolyte membrane fuel cells (PEMFC) - a review, J. Power Sources 231 (2013) 264-278.

[7] J. Miyake, K. Miyatake, Fluorine-free sulfonated aromatic polymers as proton exchange membranes, Polym. J. 49 (2017) 487-495.

[8] H. Pua, Y. Qina, L. Tanga, X. Tenga, Z. Changa, Studies on anhydrous proton conducting membranes based on imidazole derivatives and sulfonated polyimide, Electrochim. Acta 54 (2009) 2603-2609.

[9] F. Alcaide, G. Àlvarez, L. Ganborena, J.J. Iruin, O. Miguel, J. Alberto Blazquez, Proton-conducting membranes from phosphotungstic acid-doped sulfonated polyimide for direct methanol fuel cell applications, Polym. Bull. 62 (2009) $813-827$.

[10] A. Al-Othman, A.Y Tremblay, W. Pell, S. Letaief, TJ. Burchell, B.A. Peppley, M. Ternan, Zirconium phosphate as the proton conducting material in direct hydrocarbon polymer electrolyte membrane fuel cells operating above the boiling point of water, J. Power Sources 195 (2010) 2520-2525.

[11] J. Roeder, H. Silva, S.P. Nunes, A.T.N. Pires, Mixed conductive blends of SPEEK/ PANI, Solid State Ionics 176 (2005) 1411-1417.

[12] J. Yang, P. Kang Shen, J. Varcoe, Z. Wei, Nafion/polyaniline composite membranes specifically designed to allow proton exchange membrane fuel cells operation at low humidity, J. Power Sources 189 (2009) 1016-1019.

[13] A. Eisa, A. Al-Othman, M. Al-Sayah, M. Tawalbeh, Novel composite membranes based on polyaniline/ionic liquids for PEM fuel cells applications, Key Eng. Mater. 865 (2020) 55-60, https://doi.org/10.4028/www.scientific.net/ kem.865.55.

[14] A. Al-Othman, P. Nancarrow, M. Tawalbeh, A. Ka'ki, K. El-Ahwal, B. El Taher, M. Alkasrawi, Novel composite membrane based on zirconium phosphateionic liquids for high temperature PEM fuel cells, Int. J. Hydrogen Energy 46 (2021) 6100-6109.

[15] A. Ka'ki, A. Alraeesi, A. Al-Othman, M. Tawalbeh, Proton conduction of novel calcium phosphate nanocomposite membranes for high temperature PEM fuel cell applications, Int. J. Hydrogen Energy (2021), https://doi.org/10.1016/ j.ijhydene.2021.01.013 (Article in Press, Available online 26 January 2021).

[16] M.A.B.H. Susan, A. Noda, S. Mitsushima, M. Watanabe, Brønsted acid-base ionic liquids and their use as new materials for anhydrous proton conductors, Chem. Commun. (2003) 938-939.

[17] A. Noda, M.A.B.H. Susan, K. Kudo, S. Mitsushima, Brønsted acid-base ionic liquids as proton-conducting nonaqueous electrolytes, J. Phys. Chem. B 107 (2003) 4024-4033.

[18] H. Nakamoto, M. Watanabe, Brönsted acid-base ionic liquids for fuel cell electrolytes, Chem. Commun. (2007) 2539-2541.

[19] S.-Y. Lee, A. Ogawa, M. Kanno, H. Nakamoto, T. Yasuda, M. Watanabe, Nonhumidified intermediate temperature fuel cells using protic ionic liquids, J. Am. Chem. Soc. 132 (2010) 9764-9773.
[20] M. Diaz, A. Ortiz, I. Ortiz, Progress in the use of ionic liquids as electrolyte membranes in fuel cells, J. Membr. Sci. 469 (2014) 379-396.

[21] T. Greaves, C. Drummond, Protic ionic liquids: evolving structure-property relationships and expanding applications, Chem. Rev. 115 (2015) $11379-11448$.

[22] Q. Che, B. Sun, R. He, Preparation and characterization of new anhydrous, conducting membranes based on composites of ionic liquid trifluoroacetic propylamine and polymers of sulfonated poly (ether ether) ketone or polyvinylidenefluoride, Electrochim. Acta 53 (2008) 4428-4434.

[23] Y. Li, M. Zhang, X. Wang, Z. Li, L. Zhao, Anhydrous conducting composite membranes composed of SPEEK/silica/ionic liquids for high-temperature proton exchange, Elechtrochim. Acta 222 (2016) 1308-1315.

[24] S.-Y. Lee, T. Yasuda, M. Watanabe, Fabrication of protic ionic liquid/sulfonated polyimide composite membranes for non-humidified fuel cells, J. Power Sources 195 (2010) 5909-5914.

[25] H. Deligöz, M. Yilmazoğlu, Development of a new highly conductive and thermomechanically stable complex membrane based on sulfonated polyimide/ionic liquid for high temperature anhydrous fuel cells, J. Power Sources 196 (2011) 3496-3502.

[26] B.-K. Chen, T.-Y. Wu, C.-W. Kuo, Y.-C. Peng, I.-C. Shin, L. Hao, I.-W. Sun, 4,4'Oxydianiline (ODA) containing sulfonated polyimide/protic ionic liquid composite membranes for anhydrous proton conduction, Int. J. Hydrogen Energy 38 (2013) 11321-11330.

[27] D. Langevin, Q. Trong Nguyen, S. Marais, S. Karademir, J.-Y. Sanchez, C. Iojoiu, M. Martinez, R. Mercier, P. Judeinstein, C. Chappey, High-temperature ionicconducting material: advanced structure and improved performance, J. Phys. Chem. C 117 (2013) 15552-15561.

[28] A. Dahi, K. Fatyeyeva, D. Langevin, C. Chappey, S. Rogalsky, O. Tarasyuk, S. Marais, Polyimide/ionic liquid composite membranes for fuel cells operated at high temperatures, Elechtrochim. Acta 130 (2014) 830-840.

[29] S. Makhno, O. Tarasyuk, T. Cherniavska, O. Dzhuzha, V. Parkhomenko, S. Rogalsky, Polymer-electrolyte membrane for fuel cells based on crosslinked polyimide and protic ionic liquid, J. Chem. Technol. 25 (2018) 49-57, https://doi.org/10.15421/081708.

[30] Z. Zhao, K. Ueno, C. Austen Angell, High conductivity, and "dry" proton motion, in guanidinium salt melts and binary solutions, J. Phys. Chem. B 115 (2011) 13467-13472.

[31] H. Zhu, U. Ali Rana, V. Ranganathan, L. Jin, L.A. O'Dell, D.R. MacFarlane, M. Forsyth, Proton transport behaviour and molecular dynamics in the guanidinium triflate solid and its mixtures with triflic acid, J. Mater. Chem. A 2 (2014) 681-691.

[32] S. Fang, L. Yang, C. Wei, C. Jiang, K. Tachibana, K. Kamijima, Ionic liquids based on guanidinium cations and TFSI anion as potential electrolytes, Electrochim. Acta 54 (2009) 1752-1756.

[33] Y. Gao, S.W. Arritt, B. Twamley, J.M. Shreeve, Guanidinium-based ionic liquids, Inorg. Chem. 44 (2005) 1704-1722.

[34] H. Luo, G.A. Baker, J.S. Lee, R.M. Pagni, S. Dai, Ultrastable superbase-derived protic ionic liquids, J. Phys. Chem. B 113 (2009) 4181-4183.

[35] S. Rogalsky, J.-F. Bardeau, S. Makhno, N. Babkina, O. Tarasyuk, T. Cherniavska, I. Orlovska, N. Kozyrovska, O. Brovko, New proton conducting membrane based on bacterial cellulose/polyaniline nanocomposite film impregnated with guanidinium-based ionic liquid, Polymer 142 (2018) 183-195.

[36] M.K. Denk, X. Ye, Alkylation of ethylenethiourea with alcohols: a convenient synthesis of S-alkyl-isothioureas without toxic alkylating agents, Tetrahedron Lett. 46 (2005) 7597-7599.

[37] C. Nistor, S. Shishatskiy, M. Popa, S.P. Nunes, Composite membranes with cross-linked Matrimid selective layer for gas separation, Environ. Eng. Manag. J. 7 (2008) 653-659.

[38] A.P. Kharitonov, Yu L. Moskvin, D.A. Syrtsova, V.M. Starov, V.V. Teplyakov, Direct fluorination of the polyimide Matrimid $($ 5218: the formation kinetics and physicochemical properties of the fluorinated layers, J. Appl. Polym. Sci. 92 (2004) 6-17.

[39] F. Moghadam, M.R. Omidkhah, E. Vasheghani-Farahani, M.Z. Pedram, F. Dorosti, The effect of $\mathrm{TiO}_{2}$ nanoparticles on gas transport properties of Matrimid5218-based mixed matrix membranes, Separ. Purif. Technol. 77 (2011) 128-136.

[40] K. Yuriar-Arredondo, M.R. Armstrong, B. Shan, W. Zeng, W. Xu, H. Jiang, B. Mu, Nanofiber-based Matrimid organogel membranes for battery separator, J. Membr. Sci. 546 (2018) 158-164.

[41] J. Kiefer, J. Fries, A. Leipertz, Experimental vibrational study of imidazoliumbased ionic liquids: Raman and infrared spectra of 1-ethyl-3methylimidazolium bis(trifluoromethylsulfonyl)imide and 1-ethyl-3methylimidazolium ethylsulfate, Appl. Spectrosc. 61 (2007) 1306-1311.

[42] A. Georgiev, D. Dimov, E. Spassova, J. Assa, P. Dineff, G. Danev, Chemical and physical properties of polyimides: biomedical and engineering applications, in: M.J.M. Abadie (Ed.), High Performance Polymers - Polyimides Based from Chemistry to Applications, Tech, Rijeka, Slovenia, 2012, pp. 65-84.

[43] R. Sood, C. Iojoiu, E. Espuche, F. Gouanvé, G. Gebel, H. Mendil-Jakani, S. Lyonnard, J. Jestin, Proton conducting ionic liquid doped Nafion membranes: nano-structuration, transport properties and water sorption, J. Phys. Chem. C 116 (2012) 24413-24423. 
[44] F. Lu, X. Gao, S. Xie, N. Sun, L. Zheng, Chemical modification of Nafion membranes by protic ionic liquids: the key role of ionomer-cation interactions, Soft Matter 10 (2014) 7819-7825.

[45] S. Shi, A.Z. Weber, A. Kusoglu, Structure-transport relationship of perfluorosulfonic-acid membranes in different cationic forms, Elechtrochim. Acta 220 (2016) 517-528.

[46] M. Litt, R. Ameri, Y. Wang, R. Savinell, J. Wainwright, Polybenzimidazoles/ phosphoric acid solid polymer electrolytes: mechanical and electrical properties, Mater. Res. Soc. Symp. Proc. 548 (1998) 313-323.

[47] X. Chen, H. Tang, T. Putzeys, J. Sniekers, M. Wübbenhorst, K. Binnemans, J. Fransaer, D.E. De Vos, Q. Li, J. Luo, Guanidinium nonaflate as a solid state proton conductor, J. Mater. Chem. A 4 (2016) 12241-12252.
[48] P. Ramaswamy, N.E. Wong, G.K.H. Shimizu, MOFs as proton conductors challenges and opportunities, Chem. Soc. Rev. 43 (2014) 5913-5932.

[49] S. Liu, L. Zhou, P. Wang, F. Zhang, S. Yu, Z. Shao, B. Yi, Ionic-liquid-based proton conducting membranes for anhydrous $\mathrm{H}_{2} / \mathrm{Cl}_{2}$ fuel-cell applications, ACS Appl. Mater. Interfaces 6 (2014) 3195-3200.

[50] R. Sood, C. Iojoiu, E. Espuche, F. Gouanvé, G. Gebel, H. Mendil-Jakani, S. Lyonnard, J. Jestin, Comparative study of proton conducting ionic liquid doped Nafion membranes elaborated by swelling and casting methods: procession conditions, morphology, and functional properties, J. Phys. Chem. C 118 (2014) 14157-14168. 